\title{
EFFECT OF PARTICLE SIZE DISTRIBUTION AND MIXING HOMOGENEITY ON MICROSTRUCTURE AND HARDNESS OF SINTERED AL-TIC NANO COMPOSITES
}

\section{SIVARAJ", S. RAJKUMAR, NEGA TESFIE \& LIJALEM MULUGETA}

Department of Mechanical Engineering, Faculty of Manufacturing, Institute of Technology, Hawassa University, Ethiopia

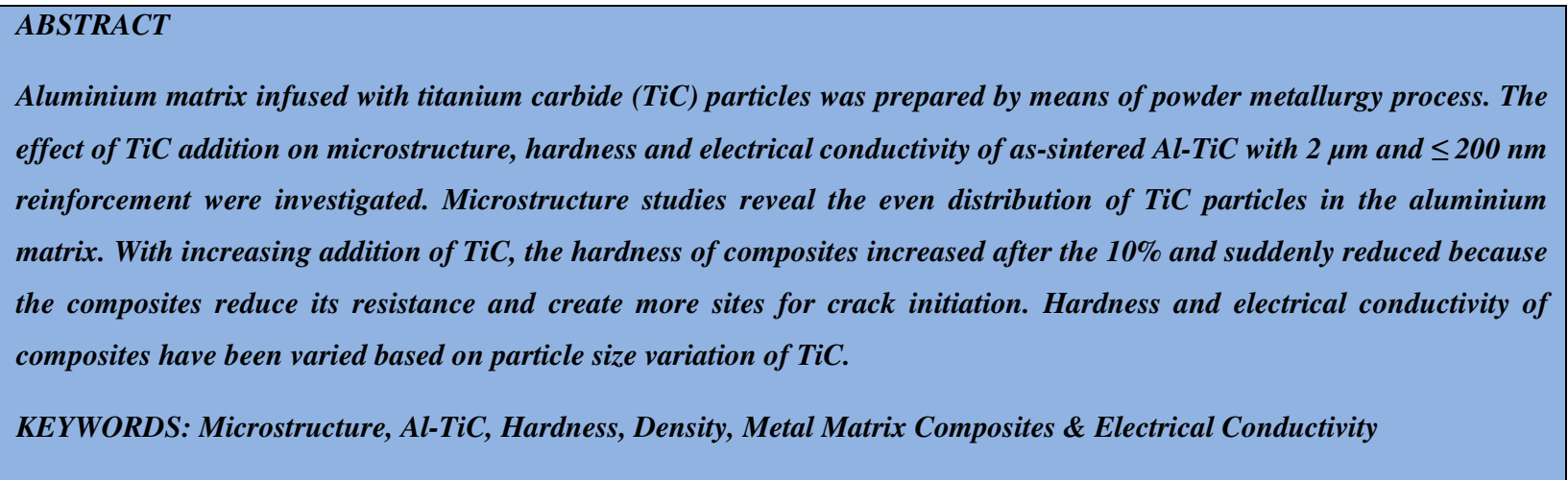

Received: Jun 08, 2020; Accepted: Jun 28, 2020; Published: Sep 03, 2020; Paper Id.: IJMPERDJUN20201041

\section{INTRODUCTION}

Metal matrix composites (MMCs) are the focus of intense research and development worldwide for many industrial branches, where reduction in weight of elements along with the improvement in specific modulus, strength, thermal stability, wear resistance, and service life are required [1-3]. Nanoparticles-reinforced aluminium matrix composites (AMCs) are a new class of nanostructured materials, consisting of ceramic nanoparticles used as reinforcements. Various kinds of ceramic nanoparticles, E.g., TiC, $\mathrm{SiC}, \mathrm{B}_{4} \mathrm{C}, \mathrm{Al}_{2} \mathrm{O}_{3}$ and $\mathrm{MgO}$ have been added to the AMCs to improve the microstructure and mechanical properties. Amongst these nanoparticles, TiC appears to be very popular, because it has a high specific strength, high modulus, low density, good wear resistance, relatively high temperature stability and good wettability with molten aluminium [4]. The aluminium alloy based metal matrix composites are generally preferred for their low density, wide alloying range, capability and response to heat treatment when used for monolithic counterparts and their intrinsic flexibility and responsiveness to processing [5-7].

In the case of Ti matrix composites, a controlled three-dimensional microstructure has the capability to enhance the properties of material, such as elastic modulus, tensile strength and fracture toughness, compared with well-distributed counterparts [8, 9]. Titanium carbide-based composites with nickel alloys and iron alloys are currently used in high performance applications where wear and corrosion are the main sources of material failure [10]. For example, additions of titanium carbide (TiC), one of the hardest refractory metal carbides, with a Vickers hardness of 19.6-31.4 GPa [11], can be expected to improve the abrasion resistance of many different alloy systems. Particle-reinforced metal matrix composite materials are used for structural applications in wear industry due to super toughness and wear resistance. Especially, alumina- and silicon carbide-based composite materials do not lose their hardness and wear resistances during high temperature applications [12-13]. 
Synthesized nano aluminium and titanium powders were conducted the safety analysis [14]. Nanoparticles have a great thermal behavior while compared with micron sized powder [15]. However, limited work has been reported about the influence of processing parameters on the behavior of alloys and composites fabricated by powder metallurgy [16-20].

Hence the current work is focused on investigating the behaviour of Al-TiC composites. Aluminium metal matrix composites reinforced with two different sizes of TiC particles at 5\% were prepared using the powder metallurgy route, and the effect of the TiC content on the microstructure, hardness behaviour of the composites was investigated.

\section{EXPERIMENTAL INVESTIGATION}

Aluminium and Titanium Carbide powders, utilized in the current research, were procured from M/s. Alfa Aesar, England. Atomized aluminium powder and $\mathrm{TiC}$ were acquired with $99 \%$ and $99.5 \%$ purity with $45 \mu \mathrm{m}$ and $2 \mu \mathrm{m}$ average particle sizes respectively. The characteristics of the aluminium and TiC powder are listed in Table $1 \& 2$. The TiC powder was pulverized in a planetary ball mill for $12 \mathrm{~h}$ and the obtained particle size was approximately below $200 \mathrm{~nm}$. The individual powders (Al, TiC) were fine-grained in a planetary ball mill using tungsten carbide grinding medium with Ball Powder Ratio (BPR) 1:20for further $1.5 \mathrm{~h}$ and later it was blended on a mass basis with $5 \%$ titanium carbide. Then the combined Al-5TiC powders were mixed systematically in the high energy planetary ball mill for another $0.25 h$ to attain homogeneous mixture. Figure 1(a) shows the initial aluminium particles at 800X magnification; the particles are spherical in structure. Figure 1(b) shows the TiC particles at 1000X magnification and it has the structure of a pancake. Further Figure 1(c) shows Al-5TiC mixed powder after milling for $0.25 \mathrm{~h}$.

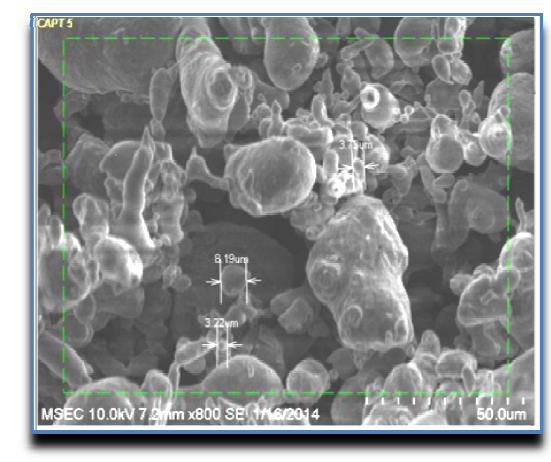

(a) pure Al

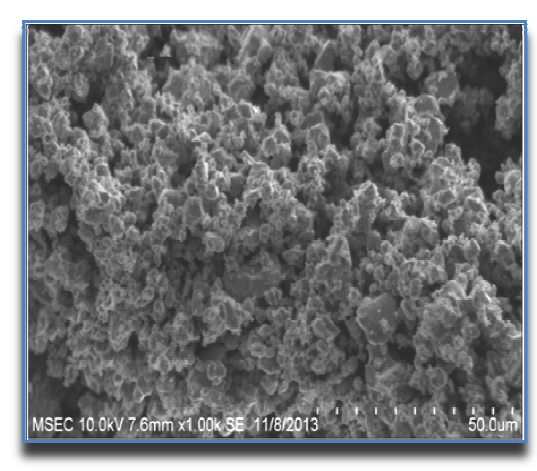

(b) pure $\mathrm{TiC}$

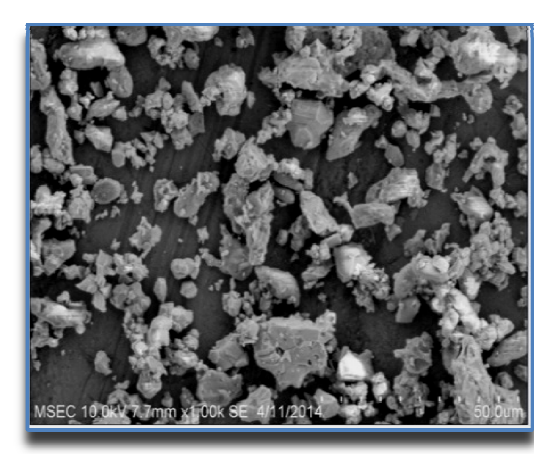

c) Al-5TiC mixed powder

Figure 1: (a-c) SEM Morphology

A cylindrical compact (Al-5TiC) was prepared using two separate particle size TiC namely $2 \mu \mathrm{m} \& \leq 200 \mathrm{~nm}$ with $15 \mathrm{~mm}$ diameter \& aspect ratio 1 . This was compacted in a compression testing machine with $1.0 \times 10^{6} \mathrm{Ncapacity}$ using the die set (figure 2). A compacting pressure of $6.7 \times 107 \mathrm{~N} / \mathrm{mm}^{2}$ was applied to acquire the aspect ratio. Zinc-sterate was utilized to lubricate the die set; the density variation and aspect ratio were sustained by mass and compacting pressure. Compacts with Metal Powder Industries Federation (MPIF) standard 42 were utilized [21]. 
Table 1: Characteristics of Aluminium Powder

\begin{tabular}{|l|c|c|}
\hline \multirow{4}{*}{ Aluminium } & Sieve size $(\boldsymbol{\mu m})$ & Wt. \% \\
\cline { 2 - 3 } & +106 & 00.26 \\
\cline { 2 - 3 } & +90 & 02.54 \\
\cline { 2 - 3 } & +75 & 14.73 \\
\cline { 2 - 3 } & +63 & 17.58 \\
\cline { 2 - 3 } & +53 & 24.86 \\
\cline { 2 - 3 } & +45 & 12.33 \\
\cline { 2 - 3 } & +38 & 06.27 \\
\cline { 2 - 3 } & -38 & 21.42 \\
\hline Apparentdensity $\left(\mathrm{g}^{\mathrm{c}} \mathrm{cm}^{-3}\right)$ & & 1.030 \\
\hline Flow rate, $\left(\right.$ by Hall flow meter) $\left(50 \mathrm{~g}^{-1}\right)$ & & 32.00 \\
\hline Particle size-dry sieve test standard & & ASTMB-214 \\
\hline
\end{tabular}

Table 2: Characteristics of Titanium Carbide Powder

\begin{tabular}{|l|c|}
\hline Purity $\%$ & 99.50 \\
\hline Sieve size $(\mu \mathrm{m})$ & 2.00 \\
\hline Density $\left(\mathrm{g} . \mathrm{cm}^{-3)}\right.$ & 4.93 \\
\hline Melting point ${ }^{0} \mathrm{C}$ & 3,140 \\
\hline
\end{tabular}

After compaction, the preforms were removed from the die set assembly and loaded into the furnace for sintering. The sintering was carried out in an inert argon gas (to prevent oxidization) circulating furnace at $575^{\circ} \mathrm{C}$ for a period of $1 \mathrm{~h}$. After that the sintered preforms were left in the furnace to cool until it reaches room temperature. A fine wire brush was used to clean the preforms after taking out from the furnace. The density of green compacts, as sintered specimens, was determined using the Archimedes principle [22]. Mustard oil was used as the immersion fluid [23]. Three polished samples were randomly weighed using an electronic weight with an accuracy of $\pm 0.001 \mathrm{~g}$ and were immersed in pure water. Vickers hardness measurements were made on Al-5TiC performs in sintered conditions with a load of $500 \mathrm{~g}$ dwelling for $10 \mathrm{~s}$.

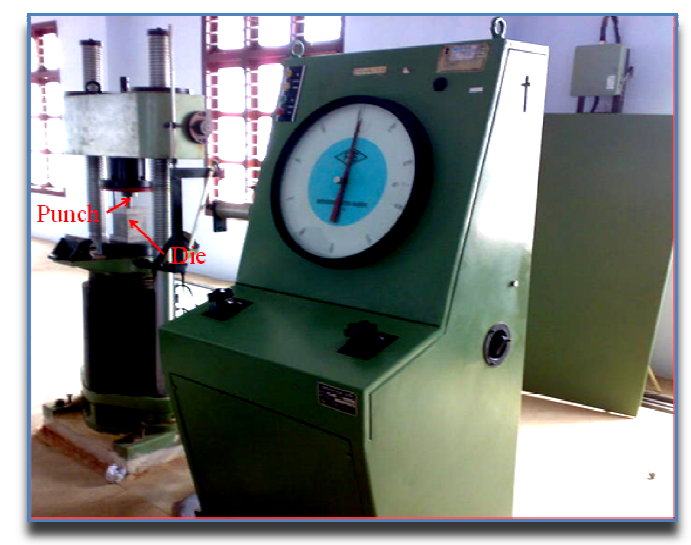

Figure 2: Compaction Methodology.

The electrical conductivity of Al-TiC composite was evaluated with eddy current instruments in accordance with ASTM standard E1004-02 [24]. The electrical conductivity measured by this equipment is usually expressed as a percentage of the conductivity of the International Annealed Copper Standard (\% IACS). For metallographic study, the samples were prepared according to the standard metallographic procedure. X-ray diffraction (XRD), Energy Dispersive Analysis (EDA) and Field Emission Scanning Electron Microscope (FESEM) were used to investigate microstructure and phase composition of composites. 


\section{RESULTS AND DISCUSSIONS}

The Al-TiC composites were successfully produced using the cold pressing method together with a sintering time of $1 h$ at $575^{\circ} \mathrm{C}$, under a compacting pressure of $6.7 \times 10^{7} \mathrm{~N} / \mathrm{mm}^{2}$. The theoretical density was measured at $90 \%$ in $2 \mu \mathrm{m} \& 95 \%$ in $\leq 200 \mathrm{~nm}$ composites for the same compaction pressure. Microstructural evaluation studies were conducted by FESEM. The composite specimen showed the uniform distribution of reinforced particles. Observations reveal minimum presence of porosity in the materials [25]. Figure 3\& 4 shows the FESEM microstructure of the sintered composite samples of Al-5TiC with $2 \mu \mathrm{m} \& \leq 200 \mathrm{~nm}$ TiC particles respectively. A close observation of the above micrographs indicates the even distribution of $\mathrm{TiC}$ particles in the aluminium matrix Al-5TiC $(\leq 200 \mathrm{~nm})$ composites when compared to Al-5TiC $(2 \mu \mathrm{m})$ which shows slight agglomeration. It is very important to obtain homogeneous distribution of reinforcement in the matrix in order to enhance mechanical, electrical and thermal properties [26].

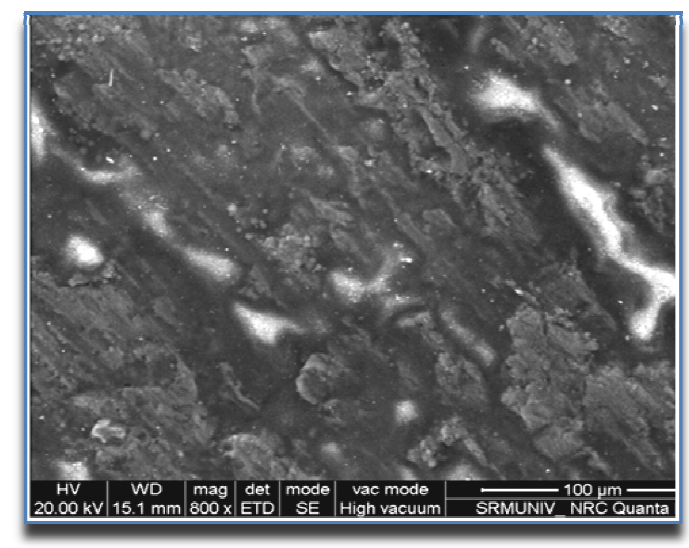

Figure 3: FESEM Image of Composite Mixture of Al$5 \mathrm{TiC}(2 \mu \mathrm{m})$.

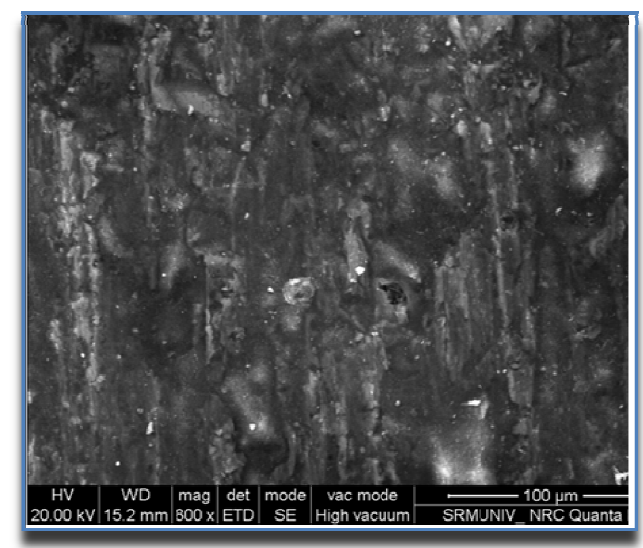

Figure 4: FESEM Image of Composite Mixture of Al$\mathbf{5 T i C}(\leq 200 \mathrm{~nm})$.

The XRD analysis was performed for $\mathrm{Al}$ composite with $2 \mu \mathrm{m}$ and $200 \mathrm{~nm}$ in order to determine whether a phase formed to provide bonding in the interface of aluminium (matrix) and titanium carbide (reinforcement) particles or not.The studies on made-up materials [Figure $5 \& 6$ ] point out the incidence of phases such as Al, TiC. XRD analysis of the sintered samples reveals the absence of any intermetallic, and reaction phase in the composites. The phase progression in the sintered composites was the same irrespective of the amount of TiC reinforcement. The diffraction patterns of the Al-TiC composites exhibits a variety of peaks matching to the Face Centred Cubic (FCC) phase of aluminium and TiC peaks to that of JCPDS file numbers 04-0787 \& 32-1383 respectively. Figure 5 \& 6 shows the Al reflecting planes (111), (200), (220) \& (311) and TiC reflecting planes (111), (200), (220) \& (311) obtained during XRD [31]. Energy Dispersive Analysis (EDA) results are exhibited in Figure $7 \& 8$. Figure 7 shows an enhanced the incidence of Aland $O$ in the pure aluminium specimen. Figure 8 shows the incidence of $\mathrm{Ti}, \mathrm{Al}$ and $\mathrm{C}$ particles in the fabricated Al-TiC composite. 

and Hardness of Sintered Al-Tic Nano Composites

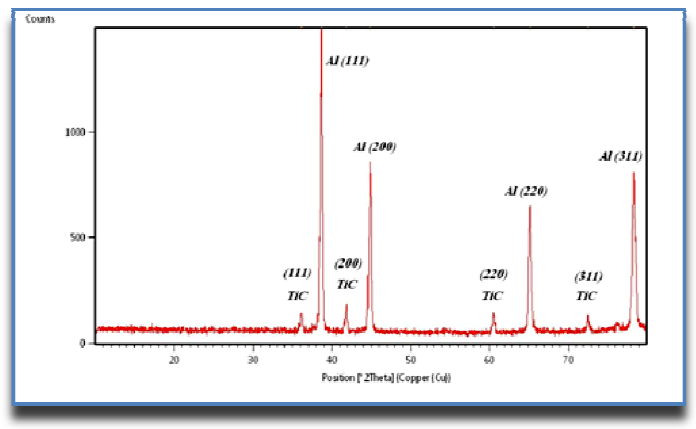

Figure 5: XRD Pattern of Various Composite of Al$5 \mathrm{TiC}(2 \mu \mathrm{m}$.

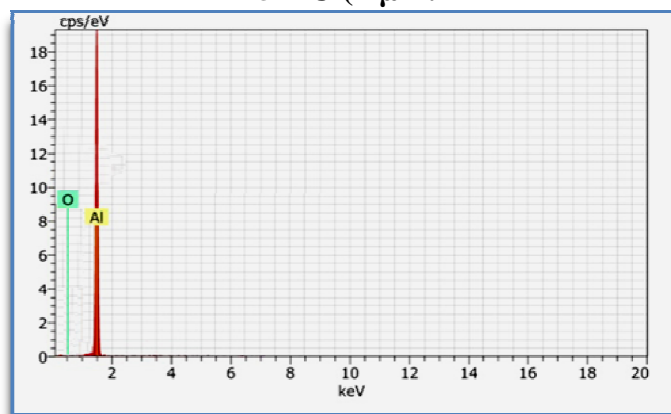

Figure 7: EDA Spectrum of a Aluminium Composite After Sintering.

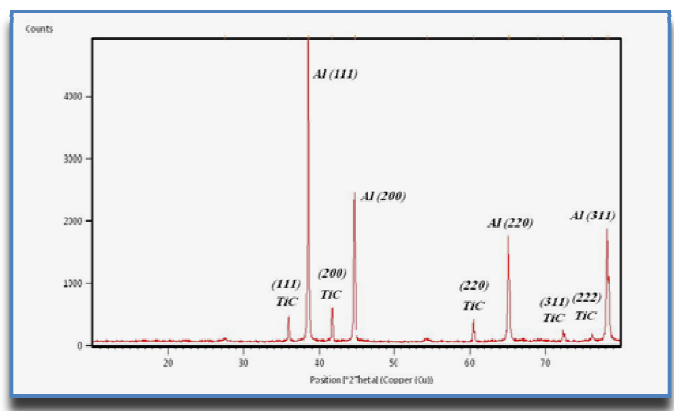

Figure 6: XRD Pattern of Various Composite of Al-5TiC $(\leq \mathbf{2 0 0} \mathbf{~ n m})$.

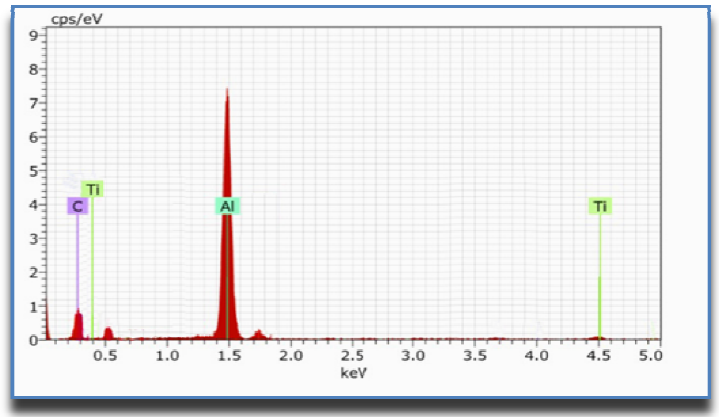

Figure 8: EDA Spectrum of an Al-5TiC Composite after Sintering.

Vickers hardness measurements were made on Al-5TiC samples in sintered conditions with a load of $500 \mathrm{~g}$ dwelling for $10 s$. At least three measurements of hardness were performed on each sample and the average values are shown in table 3 .

\begin{tabular}{|c|}
\hline Table 3: Vickers Hardness of Al-5TiC Sintered Composite \\
\hline Vickers Hardness (Hv) $\mathbf{5 0 0 g}, \mathbf{1 0 s}$ \\
\hline TiC of $\leq 200 \mathrm{~nm}$ size TiC of $2 \mu \mathrm{m}$ size \\
\hline 41.534 .5 \\
44.636 .4 \\
45.636 .2 \\
\hline
\end{tabular}

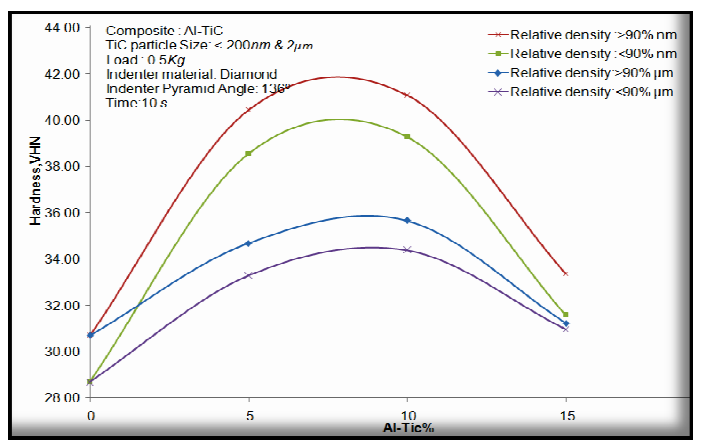

Figure 9: Hardness Value of Various Composites.

A Vickers hardness test was carried out on the composite samples (Table 3) and it shows an increase in the hardness value of the composite samples as the particle size of titanium carbide reduces. The work piece used in this experiment was Al-5TiC composites of TiC particles reinforcements $(2 \mu \mathrm{m}$ and $\leq 200 \mathrm{~nm}$ ). Figure 9 reveals the manner by which the diffused nano-TiC reinforcement led to a substantial rise in hardness of aluminium nano composites. This is 
credited to the occurrence of the moderately reduced grain size, harder ceramic TiC particulates in the matrix, their powerful resistance on the ductile aluminium matrix. Further observation indicates that, the preforms with higher relative density $(>90 \%)$ posses better hardness compared to less relative density $(<90 \%)$ preforms. The hardness of the composites decreases with an increase in particle reinforcement above $10 \%$. The composites reduce its resistance and create more sites for crack initiation and hence lower down the load-bearing capacity of the reinforcement [27-33]. The particles are no longer isolated with the ductilealuminium alloy matrix since the number of contacts between $\mathrm{TiC}$ particle increases. Therefore, cracks will not get arrested by the ductile matrix and propagate easily between titanium carbide particulate [31].

Table 4: Electrical Conductivity of Al-TiC Composites

\begin{tabular}{|c|c|c|}
\hline \multirow{2}{*}{$\% \mathbf{T i C}$} & \multicolumn{2}{|c|}{ Electrical conductivity \% IACS } \\
\cline { 2 - 3 } & $\mathbf{T i C}$ of $\leq \mathbf{2 0 0} \mathbf{n m}$ size & TiC of $\mathbf{2} \boldsymbol{\mu m}$ size \\
\hline 0 & 61 & 61 \\
\hline 5 & 52.5 & 53.2 \\
\hline 10 & 44.6 & 45.2 \\
\hline 15 & 39.5 & 40.2 \\
\hline
\end{tabular}

Table 4 illustrates the results of electrical conductivity of Al-TiC composites, produced via compacting method, based on content of titanium carbide with $2 \mu \mathrm{m} \& \leq 200 \mathrm{~nm}$ respectively. With the increase in addition rates of titanium carbide, the electrical conductivity of composites decreased. While the electrical conductivity of $\mathrm{Al}$ with no addition was measured as $61 \%$ IACS, the electrical conductivity of aluminium matrix Al-5TiC $(2 \mu \mathrm{m})$ composites with 5, 10 and 15\% TiC addition was measured as 53.2, 45.2 and 40.2\% IACS, and the electrical conductivity of aluminium matrix Al$5 \mathrm{TiC}(\leq 200 \mathrm{~nm})$ composites with 5,10 and $15 \% \mathrm{TiC}$ addition was measured as 52.5, 44.6 and $39.5 \%$ IACS, respectively.

Porosity and oxidation could be asserted as the reason for low electrical conductivity of pure $\mathrm{Al}$ [32]. Interaction between free electrons and nucleus is weak in the metals. Therefore, electrons easily move and accordingly electrical conductivity of metals is good. However, electrons are firmly bonding to the nucleus in the carbides and electrons do not move. For this reason, electrical conductivity of carbides is weak [33]. Since rate of $\mathrm{Al}$ matrix in $\mathrm{TiC}$ addition in the Al-TiC composite decreased, it is an expected result that electrical conductivities of the composites would decrease with increasing addition of TiC. Reinforced TiC particles in the composite exhibited an effect inhibiting the movement of Al electrons.

The decrease of electrical conductivity with increasing the TiC content may be related to the following several aspects. Firstly, the increase of TiC content can certainly lead to the decrease of the electrical conductivity due to the intrinsic high electrical resistivity of TiC. Secondly, with increasing the TiC content, the density of dislocations induced by the difference of thermal expansion coefficients between $\mathrm{TiC}$ and $\mathrm{Al}$ matrix increases. Increased dislocation density intensifies the scattering of electrons on interface $\mathrm{Al}-\mathrm{TiC}$, resulting in decreased electrical conductivity. And finally, the presence of $\mathrm{TiC}$ can effectively refine the grains of Al-TiC composite. Further observation indicates that, the electrical conductivity in the aluminium matrix Al-5TiC $(\leq 200 \mathrm{~nm}$ ) composites shows slight reduction compared to Al-5TiC ( $2 \mu \mathrm{m})$ because the strength and hardness of the composites increase with the increasing amount and size variation of particle reinforcement.

\section{CONCLUSIONS}

From the investigation of experimentation, it is concluded as below:

- Mechanical alloying method was used to prepare preforms with improved density (90\%-95\%) using mixture of $\mathrm{Al}$ $\&$ TiC powders. 
- Microstructure studies reveal that TiC particles were distributed uniformly in the Al matrix.

- The presence of $\mathrm{Al}$ and TiC was confirmed by X-ray diffraction analysis.XRD analysis of the sintered samples reveals the absence of any intermetallic, and reaction phase in the composites.

- With increasing addition of $\mathrm{TiC}$, the hardness of composites increased after the $10 \%$ and suddenly reduced because the composites reduce its resistance and create more sites for crack initiation.

- High TiC content decrease the electrical conductivity of Al-TiC composites as expected. The highest electrical conductivity for Al-TiC $(2 \mu \mathrm{m})$ composites was obtained in the Al-5\% TiC composite, with approximately $53.2 \%$ IACS.

\section{ACKNOWLEDGEMENTS}

The authors thank the Management of Department of mechanical Engineering, Faculty of Manufacturing, Institute of Technology, Hawassa university, Ethiopia for the encouragement.

\section{REFERENCES}

1. Das. K., Bandyopadhyay. TK., \& Das. S., 2002, A review on these various synthesis routes of TiC reinforced ferrous based composites. Journal of Material Science, 37, 3881-3892.

2. A.R. Kennedy \& S.M. Wyatt, 2001, Characterising particle-matrix interfacial bonding in particulate Al-TiC MMCs produced by different methods, Composites Part A: Applied Science and Manufacturing, 32, 555-559

3. Contreras, C. Angeles-Chavez, O. Flores and R. Perez, 2007, Structural, morphological and interfacial characterization of Al-Mg/TiC composites, Materials Characterization, 58, 685-693.

4. M. Fattahi, M. Mohammady, N. Sajjadi, M. Honarmand, Y. Fattahi and S. Akhavan, 2015, Effect of TiC nanoparticles on the microstructure and mechanical properties of gas tungsten arc welded aluminum joints, Journal of Materials Processing Technology, 217, 21-29.

5. S.F. Hassan and M.Gupta, 2006, Effect of type of primary processing on the microstructure, CTE and mechanical properties of magnesium/alumina nano composites, Composite Structures, 72, 19-26.

6. Lailesh Kumar, Syed NasimulAlam, Santosh Kumar Sahoo, 2016, Mechanical properties, wear behavior and crystallographic texture of Al-multiwalled carbon nanotube composites developed by powder metallurgy route, Journal of Composite Materials, 51, 1099-1017.

a. Santos, V. Gallegos, R. Martínez. S., 2010, Mechanical and microstructural characterization of dispersion strengthened Al-C system nano composites, Journal of Alloys and Compounds, 489, 626-630.

7. Huang J T, Lin J L, 2002, Optimization of turning operations with multiple performance characteristics using the Taguchi method and Grey relational analysis, Journal of Technology, 17, 659-664.

8. M. Sivaraj, S. Muthuraman, N. Selvakumar\& S. Rajkumar, 2018, The Effects of TiC Reinforcement on Thermal, Electrical and Dry Sliding Wear Behaviour of Aluminium Matrix Nanocomposites, International Journal of Mechanical and Production Engineering Research and Development, Trans Stellar Publisher, Vol.8, No. 1, 2018, Page - 373-388

9. R Narayanasamy, V Senthilkumar, KS Pandey, 2007,Effect of titanium carbide particle addition on the densification behavior of sintered P/M high strength steel preforms during cold upset forming, Materials Science and Engineering : A, 456, $180-188$.

10. William D. Callister, 2001, Fundamentals of materials Science and Engineering, Wily\& Sons Inc, USA. 
11. ASTM B557M-94, 2000, American Society for Testing and Materials.

12. R.A. Varin, 2002, Intermetallic-reinforced light-metal matrix in-situ composites, Metallurgical and Materials Transactions A, $33,193-201$.

13. N. Selvakumar A. Azhagurajan, and JeyakumarSriram, 2013, Experimental analysis on nano scale flash powder composition in fireworks manufacturing, Journal of Thermal Analysis and Calorimetry, 113, 615-621.

14. Azhagurajan, N. Selvakumar M. Mohammed Yasin, 2012, Minimum ignition energy for micro and nano flash powders, Process Safety Progress, 31, 19-23.

15. F. Bardi, M. Cabibbo, E. Evangelista, S. Spigarelli and M. Vukcevic, N, 2003, analysis of hot deformation of an Al-Cu-Mg alloy produced by powder metallurgy, Materials Science and Engineering: A, 339,43-52.

16. Suresh Kumar S, Uthayakumar M, ThirumalaiKumaran S, Parameswaran P, 2015, Mohandas E, Kempulraj G, Ramesh Babu B S, Natarajan S A, Parametric optimization of wire electrical discharge machining on aluminium based composites through grey relational analysis, Journal of .Manufacturing Processes, 20, 33-39.

17. Patel K M, PulakPandey M, VenkateswaraRao P, 2008, Understanding the role of weight percentage and size of silicon carbide particulate reinforcement on electro-discharge machining of aluminum-based composites, Material Manufacturing Process, 23, 665-673.

18. H.C. Wu, R.C. Chang and H.C Hsiao, 2009, Research of minimum ignition energy for nano Titanium powder and nano Iron powder, Journal of Loss Prevention in the Process Industries, 22, 21-24.

19. Wu, Qianlin, Yang, Caiding, Xue, Feng, Sun, Yang Shan, 2011, Effect of Mo addition on the microstructure and wear resistance of in situ TiC/Al composite, Materials and Design, 32, 4999-5003.

20. Determination of density of compacted or sintered metal powder products; 1977, Metal Powder Industries Federation, MPIF standard 42.

21. V. Senthilkumar, A. Balaji and HafeezAhamed., 2011, Effect of Secondary Processing and Nanoscale reinforcement on the Mechanical Properties of Al-TiC Composites, Journal of Minerals and Materials Characterization and Engineering,10, 12931306.

22. Y. Liu, L.F. Chen, H.P.Tang, C.T. Liu, B. Liu and B.Y.Huang, 2007, Preparation and Mechanical Properties of ParticulateReinforced Powder Metallurgy Titanium Matrix Composites, Metallurgical and Materials Transactions A, 38, 2825-2831

23. ASTM E1004-02, Standard practice for determining electrical conductivity using the electromagnetic (eddy-current) method.

24. Kang HK. 2005, Microstructure and electrical conductivity of high volume $\mathrm{Al}_{2} \mathrm{O}_{3}$-reinforced copper matrix composites produced by plasma spray. Surface Coat Technology, 448-452.

25. N. Selvakumar and S.C. Vettivel, 2013, Thermal, electrical and wear behavior of sintered Cu-W nanocomposite, Materials and Design, 46, 16-25.

26. Malekian M, Mostofa M G, Park S S, Jun M B, 2012, Simulation and Experiments of Material-Oriented Ultra-Precision Machining, Journal of Material Process Technology, 212, 553-559

27. Suresh Kumar S, Uthayakumar M, ThirumalaiKumaran S, Parameswaran P, 2015, Mohandas E, Kempulraj G, Ramesh Babu B S, Natarajan S A, Parametric optimization of wire electrical discharge machining on aluminium based composites through grey relational analysis, Journal of .Manufacturing Processes, 20, 33-39. 
28. Suresh S, ShenbagaVinayagaMoorthi N, Vettivel S C, Selvakumar N, 2014, Mechanical behavior and wear prediction of stir cast Al-TiB2 composites using response surface methodology, Materials Design, 59, 383-396

29. Vettivel S C, Selvakumar N, Narayanasamy R, Leema N, Numerical modelling, prediction of Cu-W nano powder composite in dry sliding wear condition using response surface methodology, Material Design, 50, 2013, 977-996

30. S.F. Santos, M.C. De Andrade, J.A. Sampaio, A.B. Da Luz and T. Ogasawara, Thermal study of $\mathrm{TiO}_{2}-\mathrm{CeO}_{2}$ yellow ceramic pigment obtained by the Pechini method, Journal of Thermal Analysis and Calorimetry, 87, 743-746.

31. Chorng-JyhTzeng, Yu-Hsin Lin, Yung-Kuang Yang, Ming-Chang Jeng, 2009, Optimization of turning operations with multiple performance characteristics using the Taguchi method and Grey relational analysis, Journal of Material Process Technology, 29, 2753-2759

32. AzadiMoghaddam M, Kolahan F, 2015, Optimization of EDM process parameters using statistical analysis and simulated annealing algorithm, International Journal of Engineering, 28, 154-163.

33. Oyetunji Oluremilekun. Ropo\& Ojewande Taofik Abiodun, "Design of an Interface to Measure Thermal Conductivity in An Automated Furnace”, BEST : Journal of Management, Information Technology and Engineering ( BEST : JMITE ), Vol. 1, Issue 2, pp. 57-66

34. Hesham Elzanaty, "The Effect of Different Copper Content on Microstructure and Mechanical Properties of Zn-40Al and Al40Zn Alloys "IMPACT: International Journal of Research in Engineering \& Technology (IMPACT: IJRET), Vol. 2, Issue 7, pp. 55-62

35. Ravi Duhan \& Suraj Choudhary, "Effect of Different Fluxes on Hardness and Microstructure of SS 304 in GTAW Welding “, International Journal of Mechanical Engineering (IJME), Vol. 3, Issue 4, pp. 1-8

36. Benjamin Tawiah\& Benjamin K. Asinyo, “Advances in Spun-dyeing of Regenerated Cellulose Fibers “, BEST: International Journal of Management, Information Technology and Engineering (BEST: IJMITE), Vol. 4, Issue 2, pp. 65-80 
